\title{
Accessory Parotid Gland Tumour - A Case Report
}

Dr. Byreddy Aishwarya ${ }^{1 *}$, Dr. Kanubaddy Sridhar Reddy ${ }^{2}$

${ }^{1}$ Post graduate, ${ }^{2}$ Associate professor, Department of Oral and Maxillofacial Surgery, Narayana Dental College and hospital, Nellore, 524003 Andhra Pradesh, India

DOI: $\underline{10.36347 / \text { sasjs.2021.v07i04.007 }}$

| Received: 27.02.2021 | Accepted: 01.04.2021 | Published: 09.04.2021

*Corresponding author: Dr. Byreddy Aishwarya

Abstract

The accessory parotid gland is an anatomical variation with incidence of approximately $21 \%$. It is the aggregation of salivary tissue anterior to and anatomically separated from main parotid gland which is located adjacent to the parotid duct. Tumours arising from accessory parotid gland are extremely rare with reported incidents of 1 to $7.7 \%$ of all parotid gland tumours. This article illustrates a case of 35-year-old male patient with swelling in the right cheek region since 4 years.

Keywords: Mid-cheek masses, accessory parotid gland, pleomorphic adenoma.

Copyright $(\mathcal{C} 2021$ The Author(s): This is an open-access article distributed under the terms of the Creative Commons Attribution 4.0 International License (CC BY-NC 4.0) which permits unrestricted use, distribution, and reproduction in any medium for non-commercial use provided the original author and source are credited.

\section{INTRODUCTION}

Accessory parotid gland is the normal salivary tissue separated from the main parotid gland, located approximately $6 \mathrm{~mm}$ anterior to main parotid gland between skin and masseter muscle, along an imaginary line that extends from tragus to a point midway between ala of nose and vermilion border of lip [1]. Accessory parotid gland is found between or deep to zygomatic and buccal branches of facial nerve. It is $0.5-1 \mathrm{~cm}$ diameter in size. It has a secondary duct emptying into stensen's duct. It is rare and exists in $21 \%$ of individuals. The accessory parotid gland tumours are rare with a reported frequency of $1-7.7 \%$. Benign tumours account for approximately 50\% - 74\% and malignancy rate ranges from $26 \%-50 \%$ which is more than $25 \%$ malignancy reported for tumours of parotid gland proper [2].

Typically, Accessory parotid gland is undetectable clinically, it becomes noticeable as a midcheek mass secondary to underlying pathology. Surgical excision remains the treatment of choice for mid cheek masses [3]. Various surgical approaches stated in the literature include direct skin incision overlying tumour and removal, intraoral excision with or without facial nerve monitoring, face lift approach, standard parotidectomy incision with anterior approach, parotidotomy approach and minimally invasive endoscopic assisted resection with preauricular incision [4].
Johnson and Spiro suggest standard parotidectomy incision allow for maximal surgical exposure of lesion and enables identification of distal facial nerve branches for preservation of nerve function [5].

This article presents a case report of 35-yearold male patient with accessory parotid gland tumour on right cheek region.

\section{CASE REPORT}

A 35-year-old male patient reported to the department with a chief complaint of swelling in the right cheek region since 4 years. Swelling was asymmetric, slow growing and poorly localised in the right cheek region.

On extraoral examination, mild facial asymmetry noted due to fullness of cheek and overlying skin is normal in texture on right side. Swelling was firm in consistency, nontender on palpation. It was mobile and not fixed to underlying structures. Right submandibular lymph nodes were palpable. An oval to round swelling of size $4.5 \mathrm{~cm} \mathrm{X} 5 \mathrm{~cm}$ extending $1 \mathrm{~cm}$ below the infraorbital rim to $0.5 \mathrm{~cm}$ above the right lower border of the mandible superioinferiorly and from corner of the mouth to $2 \mathrm{~cm}$ in front of right pretragus anterioposteriorly (Fig 1A, B). 
On intraoral examination, no visible swelling noted on inspection and hyperkeratosis was noted on buccal mucosa along the occlusal plane. Swelling extends from upper vestibular region to $1 \mathrm{~cm}$ above the lower vestibular superioinferiorly and from commissure of lip to pterygomandibular raphe anteroposteriorly on palpation (Fig-1C).

Axial section of computed tomography revealed fairly well-defined heterogeneous soft tissue opacity noted in right buccal mucosa, lateral wall of right maxillary sinus displaced anteromedially. There is no evidence of sclerosis or erosion of underlying bones (Fig-2). The impression was given as accessory parotid gland origin tumour. Ultrasonography of swelling revealed isoechoic to hyperechoic lesion in the intermuscular plane of right masticator space at the superior margin of lateral pterygoid with well-defined capsule around it and gives impression of minor salivary gland benign mixed tumour. Incisional biopsy was performed and histopathological examination was suggestive of pleomorphic adenoma.

All the investigations were within the normal limits and the case was planned for surgical excision of tumour along with accessory parotid gland under general anesthesia by using weber ferguson incision. The mass was excised with it's intact capsule along with the duct and layered closure was done. Facial nerve injury was not encountered during the surgery (Fig 3 A-F).

The excised specimen was sent for histopathological examination which revealed as pleomorphic adenoma of accessory parotid gland (Fig4). The patient was followed for one year postoperatively with no recurrence.
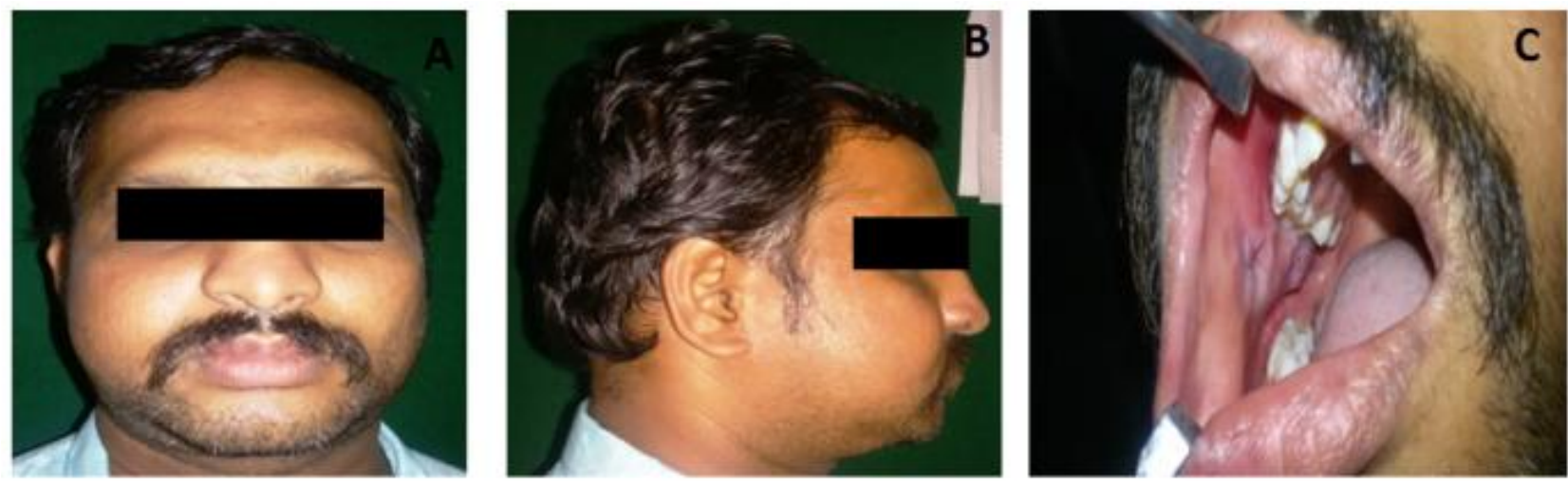

Fig-1: Pre-operative photographs; (a) Profile view, (b) Lateral view, (C) Intraoral view

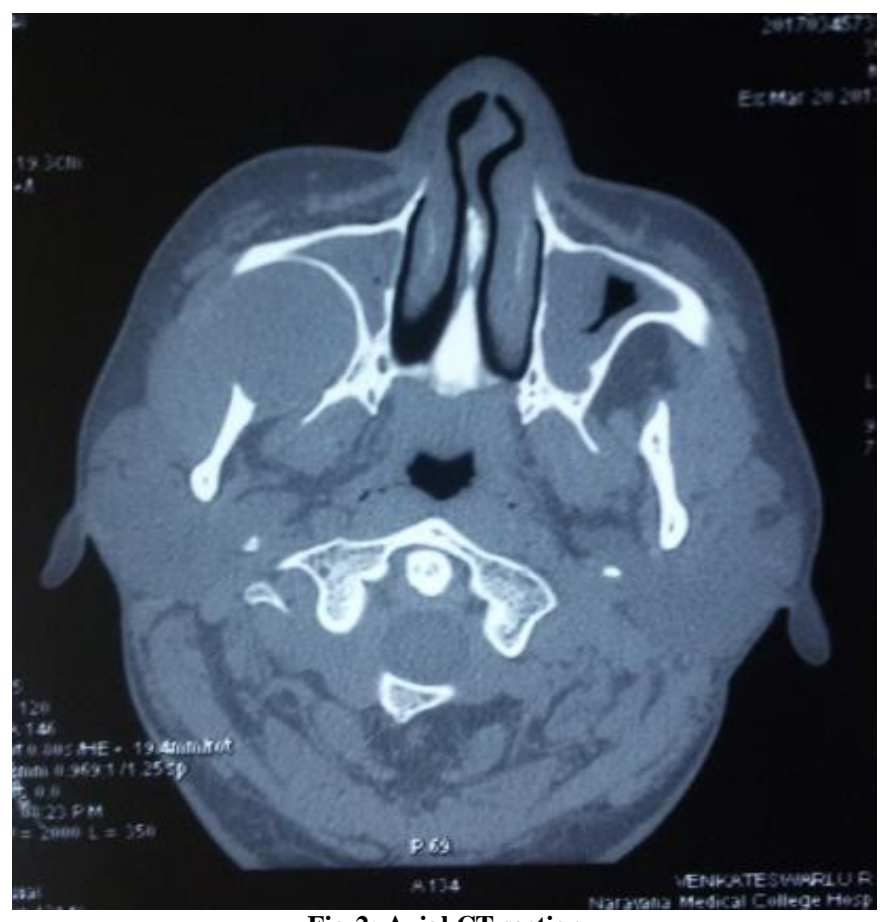

Fig-2: Axial CT section 
Byreddy Aishwarya \& Kanubaddy Sridhar Reddy., SAS J Surg, Apr, 2021; 7(4): 183-186
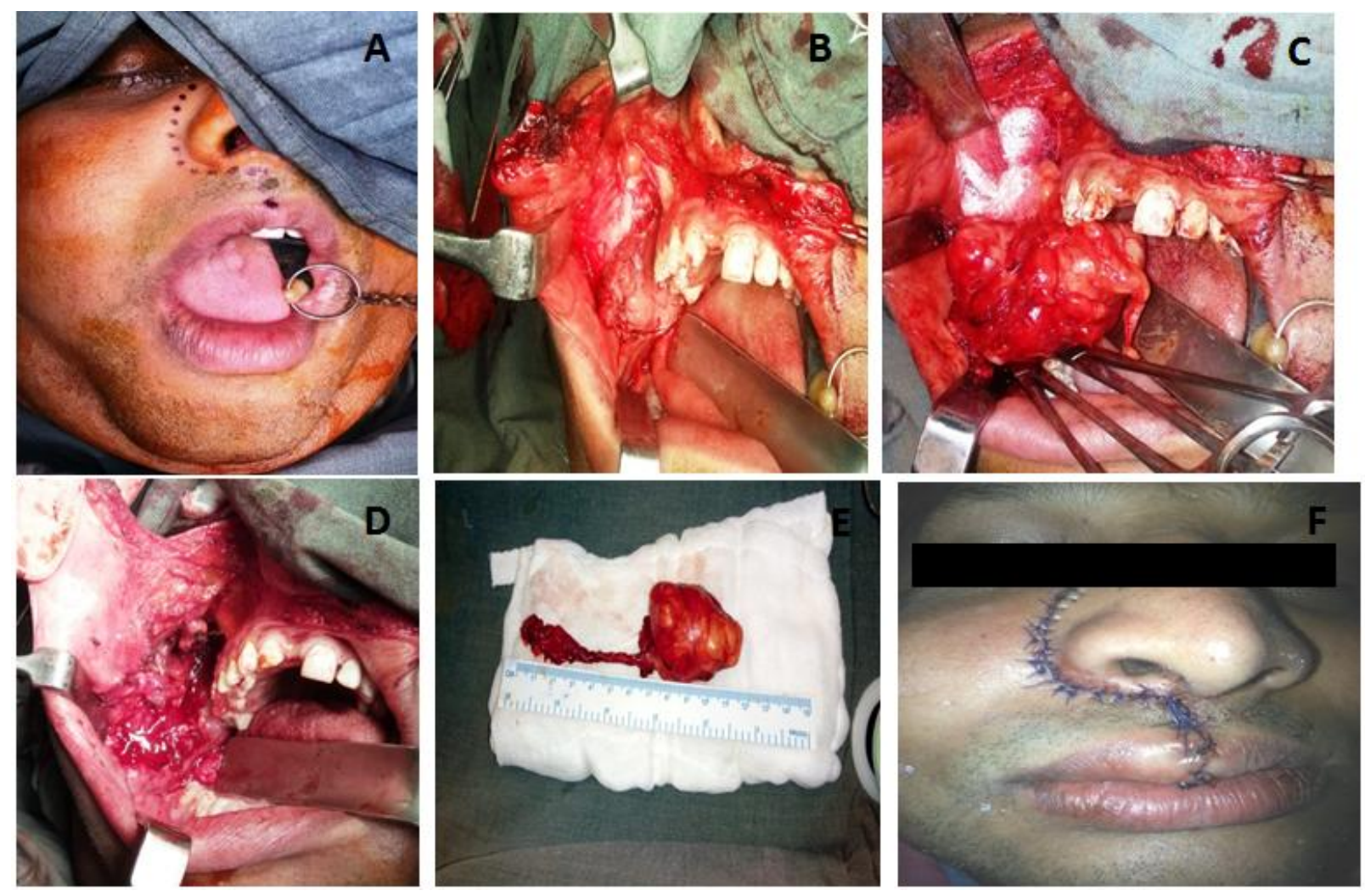

Fig-3: Intra-operative photographs; (A) Markings for incision, (B) Tumour identified after dissection, (C) Exploration of accessory parotid gland with intact capsule, (D) Defect after excision of tumour, (E) Specimen after excision of tumour with its duct, (F) Closure of the defect

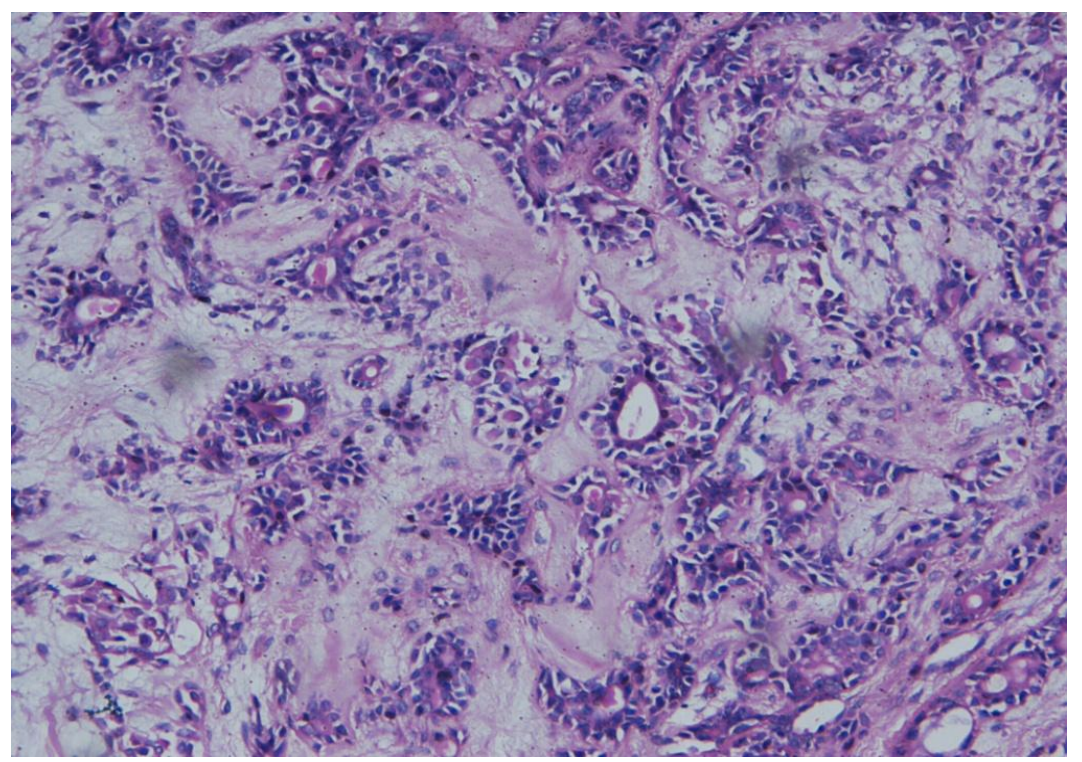

Fig-4: H\&E stained specimen of accessory parotid gland tumour shows mixture of epithelial, myoepithelial and stromal components and tumor pseudopods

\section{DISCUSSION}

A variety of diseases are known to occur within the mid-cheek region. They may arise from skin, lymphatic, adnexal, salivary structures. Differential diagnosis includes benign or malignant tumours of accessory parotid gland, parotid gland cysts, adnexal tumours, neural tumours, metastatic disease and vascular lesions [6].
Johnson and spiro in his 40-year retrospective study with 2261 patients with parotid tumours and found that $1 \%$ arouse in accessory parotid gland of these accessory parotid gland neoplasm greater than 50\% where malignant [5]. According to Perzik and White, $7.7 \%$ of tumours arise from accessory parotid gland among them $26 \%$ were malignant, $18.5 \%$ arising from the main parotid gland [7]. Histologically pleomorphic adenoma is the most common benign tumour and mucoepidermoid carcinoma being 
malignant. Diagnostic features of accessory parotid gland tumour do not differ from those of main parotid gland tumour. Proper preoperative evaluation includes a careful examination, computed tomography scans, magnetic resonance imaging and fine needle aspiration biopsy helps to establish a proper diagnosis. Magnetic resonance imaging and computed tomography are useful for visualising the separation of tumour from main parotid gland [8].

In this case, the tumour was thought to be originated from accessory parotid gland because the mass was isolated from main parotid gland and located anteriorly, the accessory duct ran from tumour to stensen's duct and salivary tissue was preserved around the tumour. Surgical excision is the first choice and it is important to identify buccal branch of facial nerve to avoid injury to facial nerve as the enlarged mass compress the buccal branch [3, 4]. Standard parotidectomy approach is safe, effective and cosmetically acceptable for surgical management of accessory parotid gland tumour. Although various incisions like standard facelift incision or an extension of incision superiorly into hairline and inferiorly into cervical crease are used to gain more access [3]. Direct incision on tumour in the cheek is not recommended because the possibility of injury to facial nerve branches is high [9]. Weber Ferguson approach was used by author's will, as this approach cause little injury to facial nerve branches and gains direct access to the surgical site.

To conclude, APG tumours are extremely rare and represent a diagnostic problem. Masses arising in the mid cheek region may often be overlooked. So proper pre-operative workup like careful physical examination, CT scans, ultrasound, MRI, fine needle aspiration biopsy and appropriate surgical approach are necessary for the successful management of these lesions.

\section{REFERENCES}

1. Frommer J. The human accessory parotid gland: its incidence, nature, and significance. Oral Surg Oral Med Oral Pathol Oral Radiol Endod. 1997; 43: 671-676.

2. Toh H, Kodama J, Fukuda J, Rittman B, Mackenzie I. Incidence and histology of human accessory parotid glands. The Anatomical Record. 1993 Jul;236(3):586-90.

3. Choi HJ, Lee YM, Kim JH, Tark MS, Lee JH. Wide excision of accessory parotid gland with anterior approach. Journal of Craniofacial Surgery. 2012 Jan 1;23(1):165-8.

4. Newberry TR, Kaufmann CR, Miller FR. Review of accessory parotid gland tumors: pathologic incidence and surgical management. American journal of otolaryngology. 2014; 35(1):48-52.

5. Johnson FE, Spiro RH. Tumors arising in accessory parotid tissue. Am J Surg. 1977; 138:576-578.

6. Osborne RF. Squamous cell carcinoma of the accessory parotid gland. Ear Nose Throat J. 2007; 86:602.

7. Perzik SL, White IL. Surgical management of preauricular tumors of the accessory parotid apparatus. Am J Surg. 1966; 112:498-503.

8. Lewkowicz A, Levy Y, Zeltser R, Zagury A, Nahlieli O. Accessory parotid gland masses. Oral Surgery, Oral Medicine, Oral Pathology, Oral Radiology, and Endodontology. 2000 May 1;89(5):610-2.

9. Lin DT, Coppit GL, Burkey BB, Netterville JL. Tumors of the accessory lobe of the parotid gland: a 10- year experience. The Laryngoscope. 2004 Sep;114(9):1652-5. 